\title{
Caracterização biométrica e acúmulo de nutrientes em porta-enxertos de caramboleira cultivada em solução nutritiva ${ }^{1}$
}

\author{
Biometric characterization and nutrient accumulation in rootstocks of the starfruit \\ cultivated in a nutrient solution
}

\author{
Danilo Eduardo Rozane ${ }^{2 *}$, Renato de Mello Prado ${ }^{3}$, William Natale ${ }^{3}$, Liliane Maria Romualdo ${ }^{4}$ Claudenir \\ Facincani Franco 5
}

\begin{abstract}
RESUMO - O conhecimento sobre o crescimento e o acúmulo de nutrientes em hipobiotos de caramboleira permite melhor eficiência da adubação na produção de hipobiotos (porta-enxertos). Objetivou-se determinar o crescimento e o acúmulo de nutrientes em hipobiotos de caramboleira cultivada em solução nutritiva. $\mathrm{O}$ experimento constituiu de cinco tratamentos, referentes aos tempos de coleta 25; 50; 75; 100 e 125 dias após o transplantio, dispostos em delineamento inteiramente casualizado em seis repetições. As plantas utilizadas foram obtidas de sementes de frutos de caramboleira 'Malásia', cultivadas em vasos com solução nutritiva. Nos diferentes órgãos dos hipobiotos (folhas, caule e raízes), avaliou-se o crescimento e o acúmulo de nutrientes e os índices nutricionais, a cada 25 dias. O ponto de enxertia $(6 \mathrm{~mm})$ foi atingido aos 110 dias após o transplantio. A ordem decrescente dos nutrientes acumulados em cada hipobioto produzido é de (em mg por planta): $\mathrm{N}=634$; $\mathrm{K}=368 ; \mathrm{Ca}=152 ; \mathrm{Mg}=106 ; \mathrm{S}=98 ; \mathrm{P}=88$ (em $\mu$ g por planta) de: $\mathrm{Fe}=2.963 ; \mathrm{Mn}=2.165 ; \mathrm{B}=722 ; \mathrm{Zn}=780, \mathrm{e} \mathrm{Cu}=96 . \mathrm{O}$ acúmulo médio de nutrientes é maior nas folhas $>$ caule $=$ raízes. O período de maior exigência de nutrientes pelos hipobiotos é compreendido entre 25-75 dias após o transplantio. As diferentes taxas de acumulação líquida dos nutrientes, nas diferentes partes da caramboleira, nem sempre acompanham a taxa de acumulação de nutrientes do respectivo órgão.
\end{abstract}

Palavras-chave - Averrhoa carambola L.. Requerimento nutricional. Marcha de absorção.

\begin{abstract}
Knowledge of the growth of, and nutrient accumulation in rootstock of the star fruit leads to a more efficient fertilization in the production this rootstock. The objective was to determine the growth of, and nutrient accumulation in rootstock of the star fruit when grown in a nutrient solution. The experiment consisted of five treatments, related to the period of collection: 25; 50; 75; 100 and 125 days after transplanting, arranged in a completely randomized design with six replications. The plants used were obtained from seeds of the fruit of the 'Malaysia' carambola, grown in pots with a nutrient solution. The growth, accumulation of nutrients, and nutritional indices of different organs of the rootstock (leaves, stems and roots) were assessed every 25 days. The grafting point $(6 \mathrm{~mm})$ was reached at 110 days after transplanting. In decreasing order, the nutrients accumulated in each rootstock produced were (mg per plant): $\mathrm{N}=634, \mathrm{~K}=368, \mathrm{Ca}=152, \mathrm{Mg}=106$, $\mathrm{S}=98, \mathrm{P}=88$, and ( $\mu$ g per plant): $\mathrm{Fe}=2,963, \mathrm{Mn}=2,165, \mathrm{~B}=722 ; \mathrm{Zn}=780$ and $\mathrm{Cu}=96$. The average accumulation of nutrients was higher in the leaves $>$ stems $=$ roots. The period of greatest nutrient demand by the rootstock occurred between 25-75 days after transplanting. The different net rates of accumulation of nutrients in the various parts of the star fruit do not always follow the rate of nutrient accumulation in the respective organ.
\end{abstract}

Key words: Averrhoa carambola L.. Nutritional requirements. Absorption rate.

\footnotetext{
*Autor para correspondência

${ }^{1}$ Recebido para publicação em 11/03/2010; aprovado em 03/03/2013

Pesquisa financiada pela FAPESP, pela concessão de Auxílio à Bolsa do primeiro autor

${ }^{2}$ Universidade Estadual Paulista “Julio de Mesquita Filho"/Unesp, Campus Experimental de Registro, Rua Nelson Brihi Badur 430, Vila Tupy, 11.900-000, Registro-SP, Brasil, danilorozane@ registro.unesp.br

${ }^{3}$ Departamento de Solos e Adubos, Faculdade de Ciências Agrárias e Veterinárias/Unesp, Jaboticabal-SP, Brasil, rmprado@fcav.unesp.br; natale@fcav.unesp.br

${ }^{4}$ Programa de Pós-Graduação em Zootecnia, Faculdade de Zootecnia e Engenharia de Alimentos/Universidade de São Paulo/USP, Pirassununga-SP, Brasil, lilianeromualdo@yahoo.com.br

${ }^{5}$ Programa de Pós-Graduação em Produção Vegetal/Unesp/FCAV, Jaboticabal-SP, Brasil, cfafranco@hotmail.com
} 


\section{INTRODUÇÃO}

A caramboleira é originária do continente asiático e o Brasil é um dos principais produtores (ALYAHYAI et al., 2005), sendo a espécie cultivada em todo o País, principalmente nas regiões mais quentes e sem ocorrência de geadas (BASTOS, 2004).

A produção de hipobiotos e, posteriormente de mudas de caramboleira com adequado estado nutricional é um dos fatores primordiais que determina o sucesso na implantação do pomar, podendo afetar a precocidade da produção, refletindo no retorno econômico do capital investido pelo fruticultor.

Para a adequada nutrição das plantas, além da quantidade acumulada e da relação entre nutrientes, é preciso conhecer o crescimento e a marcha de absorção dos elementos ao longo do tempo, o que permitirá planejar métodos racionais de cultivo e a aplicação de fertilizantes (OLIVEIRA, 2005), contribuindo para que a cultura expresse todo seu potencial genético (AUGOSTINHO et al., 2008; FRANCO, 2008; LIMA FILHO et al., 1997). Contudo, essa informação indica apenas o total acumulado, e não o que deve ser aplicado, pois deve-se considerar a eficiência de aproveitamento de cada nutriente em função das condições de cultivo.

A determinação de índices nutricionais associado ao acúmulo de nutrientes tem auxiliado no melhor entendimento da dinâmica da marcha de absorção de nutrientes pelas plantas. Estudos realizados por Lima Filho et al. (1997); Lima Filho; Malavolta (1997); Rozane et al. (2011a, 2011b) evidenciam que as taxas de crescimento e acúmulo de nutrientes têm caracterizado a dinâmica do processo de absorção de nutrientes, e o balanço observado pelos índices nutricionais exprimem a acumulação e a redistribuição de um dado nutriente na planta, ou em órgão específico, bem como, a quantidade absorvida ou redistribuída do nutriente pelo material vegetal preexistente, durante certo intervalo de tempo, subsidiando assim as práticas e manejo do fornecimento de nutrientes associados às necessidades fisiológicas da planta pelo elemento.

Salienta-se ainda, que não foram encontradas informações científicas disponíveis na literatura nacional ou internacional sobre a demanda de nutrientes por hipobiotos de caramboleira, que possibilitem sustentar programas de adubação.

Objetivou-se com este estudo determinar o crescimento e o acúmulo de nutrientes em hipobiotos de caramboleira cultivada em solução nutritiva.

\section{MATERIAL E MÉTODOS}

O experimento foi realizado com hipobiotos (porta-enxertos) de caramboleiras, na Faculdade de
Ciências Agrárias e Veterinárias - Unesp, Campus de Jaboticabal - SP. O clima, segundo a classificação de Köeppen, é do tipo subtropical com inverno seco (Cwa), com precipitação pluviométrica média anual de $1.400 \mathrm{~mm}$, temperatura média anual de $22{ }^{\circ} \mathrm{C}$ e umidade relativa média do ar de $70 \%$. A casa de vegetação é coberta com vidro transparente, cercada lateralmente com tela (malha de $2 \mathrm{~mm}^{2}$ ) e pé-direito de $2,4 \mathrm{~m}$ de altura. A temperatura e a umidade relativa do ar média no interior da casa de vegetação foram de $20,8 \pm 8,7^{\circ} \mathrm{C}$ e $67,4 \pm 23 \%$, com picos atingindo $39,7^{\circ} \mathrm{C}$ e $99,8 \%$ respectivamente.

Os hipobiotos utilizados no experimento foram provenientes de propagação sexuada (sementes), como indicado por Donadio et al. (2001). Para isto, foram selecionados frutos maduros, emumpomar decaramboleiras adultas 'Malásia', na Estação Experimental de Citricultura de Bebedouro - SP, dos quais se extraíram as sementes, que foram cultivadas individualmente em tubetes plásticos de $53 \mathrm{~cm}^{3}$ contendo casca de pínus e vermiculita até 120 dias após sua emergência. Após esse período, as raízes das plantas foram submetidas à lavagem para a retirada de todo substrato aderido ao sistema radicular, a fim de transplantá-las para o cultivo hidropônico. Utilizou-se a solução nutritiva de Furlani et al. (1999), indicada como adequada para o cultivo de mudas de caramboleira, segundo trabalho desenvolvido por Rozane et al. (2007).

O experimento iniciou-se em 24/08/2005, sendo constituído por cinco tratamentos referentes aos tempos de coleta [25(18/09/2005); 50(13/10/2005); $75(07 / 11 / 2005) ; 100(02 / 12 / 2005)$ e $125(27 / 12 / 2005)$ dias após o transplantio (DAT)], e seis repetições, disposto em delineamento inteiramente casualizado. Os tratamentos foram estabelecidos a partir da indicação de Donadio (2001), sobre o tempo médio necessário à obtenção de um porta-enxerto de caramboleira que é de aproximadamente 120 dias, tempo esse que foi dividido em cinco tempos equidistantes para satisfazer a necessidade mínima de cinco pontos na curva resposta (THOMPSON, 2002). Cada repetição representou a média de quatro plantas, totalizando 24 hipobiotos por coleta.

A adaptação dos hipobiotos ocorreu nos primeiros 15 dias após o transplantio, sendo os mesmos mantidos em solução nutritiva completa, diluída a $1 / 4$ da concentração preconizada e, após esse período, até o final do experimento, a solução foi completa, sem diluição.

Considerou-se que o início do período experimental ocorreu com o transplantio das mudas para a solução nutritiva, sendo a primeira coleta realizada após 25 dias do transplantio. Desse modo, na primeira coleta, as plantas estiveram em contato com a solução nutritiva, sem diluição, durante 10 dias. 
As mudas foram acondicionadas em vasos de polipropileno, com $8 \mathrm{Lde}$ capacidade e formato trapezoidal (0,48 $\mathrm{m}$ de comprimento na parte superior, $0,44 \mathrm{~m}$ de comprimento na base inferior, $0,16 \mathrm{~m}$ de largura e $0,17 \mathrm{~m}$ de altura). $\mathrm{O}$ espaçamento entre plantas nos vasos foi fixo durante todo o período experimental, cerca de $0,12 \mathrm{~m}$, e o espaçamento entre os vasos na casa de vegetação foi de 0 ; 0,$050 ; 0,10 ; 0,150$ e $0,20 \mathrm{~m}$, respectivamente, nos períodos de condução de $0-25$; 26-50; 51-75; 76-100 e 101-125 dias após o transplantio. Durante o período experimental, realizou-se o rodízio dos vasos na bancada, para que todas as plantas recebessem as mesmas condições ambientais.

Para o manejo da solução nutritiva, ao longo do período de estudo, o $\mathrm{pH}$ da solução foi monitorado diariamente, utilizando-se de medidor portátil (Gehaka® 1400), ajustando-se a 5,5 $\pm 0,5$ com solução $\mathrm{NaOH}$ ou $\mathrm{HCl} 0,1 \mathrm{Mol} \mathrm{L}^{-1}$. Na mesma ocasião, foi monitorada a condutividade elétrica da solução nutritiva, com o auxílio de um condutivímetro portátil (CG 220), mantendo-a com valor entre 2,0 e $2,4 \mathrm{dS} \mathrm{m} \mathrm{m}^{-1}$. A reposição da água evapotranspirada foi realizada com água destilada. A solução nutritiva dos vasos foi oxigenada constantemente, empregando-se um borbulhador acoplado a um compressor de ar, sendo a solução renovada a cada 25 dias, na ocasião de cada coleta das plantas. Salienta-se que o manejo da solução nutritiva seguiu as recomendações de Furlani et al. (1999).

Avaliaram-se, em todas as coletas, as seguintes variáveis biométricas: altura (do colo da planta até a extremidade da última folha expandida); diâmetro do caule (a 0,08 $\mathrm{m}$ do colo da planta, determinado com o auxílio de um paquímetro digital, Mytutoyo ${ }^{\circledR} \pm 0,01 \mathrm{~mm}$ ); e a área foliar (determinada com o auxílio de um aparelho integrador de áreas portátil, LI-COR ${ }^{\circledR}$ modelo LI-3100). Em seguida, as plantas foram divididas em raízes, caule e folhas, lavadas em água destilada e secas em estufa com circulação forçada de ar, à temperatura de $65^{\circ} \mathrm{C} \pm 5$, até atingir massa constante. Determinou-se a massa da matéria seca das diferentes partes da planta e, em seguida, estes materiais foram moídos e armazenados. Na sequência, determinaram-se os teores de N, P, K, Ca, Mg, S, B, Cu, $\mathrm{Fe}, \mathrm{Mn}$ e $\mathrm{Zn}$ no tecido vegetal, empregando a metodologia descrita por Bataglia et al. (1983).

O acúmulo dos nutrientes foi obtido pelo produto entre o teor do elemento e a massa da matéria seca correspondente a cada parte da planta e época avaliada. $\mathrm{O}$ acúmulo de nutrientes na planta inteira deu-se pela soma das quantidades presentes nas raízes, no caule e nas folhas.

Com base nos resultados, foram realizadas análises de variância (teste F) para as diversas características estudadas, e conforme significância estudo da regressão, para tempo de cultivo e a correlação com o auxílio do programa AgroEstat (Barbosa; Maldonado Júnior, 2009). Em todas as variáveis, empregou-se o modelo de regressão que resultou em significância pelo teste $\mathrm{F}$, e que melhor descreveu a característica estudada.

Para o modelo logístico, empregou-se a equação 1, representada por:

$$
Y=\frac{a}{1+e^{-k(x-x c)}}
$$

onde, $a$ : é o máximo acumulado assintótico; $e$ : é o inverso do logaritmo neperiano; $k$ : é a taxa média de acúmulo; $x$ : dias após o transplantio, e $x c$ : é o tempo necessário para atingir $50 \%$ do acúmulo máximo assintótico (HOFFMAM; VIEIRA, 1977).

Foram determinados, ainda, os índices nutricionais estimados pela fórmula proposta por Welbank (1962):

$$
T A R N=\frac{(N 2-N 1)(\ln M 2-\ln M 1)}{(t 2-t 1)(M 2-M 1)}=m g \text { por } g \text { por dia }
$$

na qual, TAR: é a Taxa de absorção relativa dos nutrientes; $N 1$ e N2: são a quantidade do nutriente no órgão vegetal referente aos tempos $t 1$ e $t 2$, respectivamente; $M 1$ e $M 2$ : massa da matéria seca total da planta referente aos tempos $t 1$ e $t 2$, respectivamente, e $1 n$ é o logaritmo neperiano.

$$
T A L O N=\frac{(N 2-N 1)(\ln m 2-\ln m 1)}{(t 2-t 1)(m 2-m 1)}=m g \text { por g por dia }
$$

em que, TALON: é a Taxa de Acumulação Líquida Organogênica do Nutriente; $m 1$ e $m 2$ : são a massa da matéria seca do órgão vegetal referente aos tempos $t 1$ e $t 2$, respectivamente;

$$
T C R=\frac{(\ln M 2-\ln M 1)}{(t 2-t 1)}=m g \text { por } g \text { pordia }
$$

na qual, TCR: é a Taxa de Crescimento Relativo; $M 1$ e $M 2$ : são a massa da matéria seca do órgão ou da planta referente aos tempos $t 1$ e $t 2$, respectivamente.

\section{RESULTADOS E DISCUSSÃO}

Houve efeito significativo do tempo de cultivo sobre todas as variáveis de crescimento e acúmulo de nutrientes, apresentando-se maiores incrementos ao final do período experimental (Tabela 1 e 2).

Os hipobiotos de caramboleira, nas condições experimentais, apresentaram adequado crescimento, possibilitando que o diâmetro do caule fosse suficiente para a realização da enxertia $(6 \mathrm{~mm})$, aos 110 dias após o transplantio (DAT). 
Tabela 1 - Resumo da análise de variância e resultados médios da altura, do diâmetro do caule, da área foliar e da massa da matéria seca das raízes, do caule e das folhas de hipobiotos de caramboleira, em função do tempo de cultivo em hidroponia

\begin{tabular}{|c|c|c|c|c|c|c|c|}
\hline \multirow{3}{*}{ Causas de Variação } & \multirow{2}{*}{ Altura } & \multirow{2}{*}{ Diâmetro do caule } & \multirow{2}{*}{ Área foliar } & \multicolumn{4}{|c|}{ Massa da matéria seca } \\
\hline & & & & Raízes & Caule & Folhas & Planta inteira \\
\hline & $\mathrm{m}$ & $\mathrm{mm}$ & $\mathrm{cm}^{2}$ & ------------- & ------ g po & planta ----- & ----------------- \\
\hline Teste F & $328,83 * *$ & $612,78 * *$ & $153,55^{* *}$ & $393,45^{* *}$ & $629,78 * *$ & $1119,74 * *$ & $1286,94 * *$ \\
\hline G.L. & 4 & 4 & 4 & 4 & 4 & 4 & 4 \\
\hline S.Q. & 77,31 & 125,79 & 637,06 & 2037,32 & 87,82 & $2,84.107$ & $2,52.104$ \\
\hline $\mathrm{CV}(\%)$ & 8,7 & 4,5 & 16,8 & 11,4 & 10,7 & 6,9 & 6,6 \\
\hline
\end{tabular}

**: significativo a p<0,01; G.L. = Graus de liberdade; S.Q. = Soma de Quadrados; CV = Coeficiente de Variação

Tabela 2 - Resumo da análise de variância e resultados médios do acúmulo de nutrientes por hipobiotos de caramboleira, em função do tempo de cultivo em hidroponia

\begin{tabular}{|c|c|c|c|c|c|}
\hline Nutrientes & Causas de Variação & Raízes & Caule & Folhas & Planta Inteira \\
\hline \multirow{4}{*}{$\mathrm{N}$} & Teste F & $154,64 * *$ & $463,96 * *$ & $305,37 * *$ & $657,63 * *$ \\
\hline & G.L. & 4 & 4 & 4 & 4 \\
\hline & S.Q. & $5,69.104$ & $4,40.104$ & $6,33.105$ & $1,53.106$ \\
\hline & $\mathrm{CV}(\%)$ & 18,1 & 12,7 & 12,3 & 8,7 \\
\hline \multirow{4}{*}{$\mathrm{P}$} & Teste F & $226,67 * *$ & $137,08 * *$ & $140,29 * *$ & $392,70 * *$ \\
\hline & G.L. & 4 & 4 & 4 & 4 \\
\hline & S.Q. & 3047,51 & 1949,69 & 5411,14 & $2,97.104$ \\
\hline & $\mathrm{CV}(\%)$ & 15 & 20,6 & 17 & 11 \\
\hline \multirow{4}{*}{$\mathrm{K}$} & Teste F & $272,15^{* *}$ & $473,13 * *$ & $214,97 * *$ & $431,93 * *$ \\
\hline & G.L. & 4 & 4 & 4 & 4 \\
\hline & S.Q. & $1,68.104$ & $1,15.104$ & $2,26.105$ & $5,06.105$ \\
\hline & $\mathrm{CV}(\%)$ & 13,7 & 9,1 & 14,2 & 10,1 \\
\hline \multirow{4}{*}{$\mathrm{Ca}$} & Teste F & $132,42 * *$ & $389,44 * *$ & $196,96 * *$ & $323,04 * *$ \\
\hline & G.L. & 4 & 4 & 4 & 4 \\
\hline & S.Q. & 396,90 & 5017,27 & $5,57.104$ & $1,06.105$ \\
\hline & $\mathrm{CV}(\%)$ & 19 & 13 & 16,2 & 12,9 \\
\hline \multirow{4}{*}{$\mathrm{Mg}$} & Teste F & $117,41 * *$ & $420,41 * *$ & $305,67 * *$ & $504,05 * *$ \\
\hline & G.L. & 4 & 4 & 4 & 4 \\
\hline & S.Q. & 609,38 & 2034,67 & $2,00.104$ & $4,46.104$ \\
\hline & $\mathrm{CV}(\%)$ & 22,3 & 12,5 & 13,3 & 10,6 \\
\hline \multirow{4}{*}{ S } & Teste F & $164,49 * *$ & $373,60 * *$ & $247,12 * *$ & $482,15 * *$ \\
\hline & G.L. & 4 & 4 & 4 & 4 \\
\hline & S.Q. & 1538,90 & 1079,73 & $1,44.104$ & $3,66.104$ \\
\hline & $\mathrm{CV}(\%)$ & 18,2 & 13,6 & 14 & 10,4 \\
\hline \multirow{4}{*}{ B } & Teste F & $97,98 * *$ & $314,51 * *$ & $223,00 * *$ & $322,42 * *$ \\
\hline & G.L. & 4 & 4 & 4 & 4 \\
\hline & S.Q. & $1,30.104$ & $1,30.104$ & $1,57.106$ & $2,19.106$ \\
\hline & $\mathrm{CV}(\%)$ & 17,6 & 10,8 & 14,6 & 11,8 \\
\hline
\end{tabular}


Continuação Tabela 2

\begin{tabular}{cccccc}
\hline & Teste F & $62,83^{* *}$ & $240,45^{* *}$ & $56,01^{* *}$ & $18,67^{* *}$ \\
$\mathrm{Cu}$ & G.L. & 4 & 4 & 4 & 4 \\
& S.Q. & 4186,09 & 3555,55 & 3339,48 & $3,11.104$ \\
& CV $(\%)$ & 21,4 & 17,9 & 25,3 & 14,6 \\
\hline \multirow{3}{*}{$\mathrm{Fe}$} & Teste F & $295,41^{* *}$ & $353,27^{* *}$ & $147,44^{*}$ & $421,71^{* *}$ \\
& G.L. & 4 & 4 & 4 & 4 \\
& S.Q. & $1,33.107$ & $1,19.105$ & $2,58.106$ & $3,11.107$ \\
& CV (\%) & 11,3 & 16 & 15 & 9,9 \\
\hline \multirow{4}{*}{$\mathrm{Mn}$} & Teste F & $126,26^{* *}$ & $124,38^{* *}$ & $102,00^{* *}$ & $114,43^{* *}$ \\
& G.L. & 4 & 4 & 4 & 4 \\
& S.Q. & $4,44.104$ & $2,27.104$ & $1,71.107$ & $2,01.107$ \\
& CV $(\%)$ & 19,3 & 19,2 & 21,7 & 20,4 \\
\hline \multirow{2}{*}{$\mathrm{Zn}$} & Teste F & $161,81^{* *}$ & $120,17^{* *}$ & $110,70^{* *}$ & $165,45^{* *}$ \\
& G.L. & 4 & 4 & 4 & 4 \\
& S.Q. & $4,15.104$ & $1,90.105$ & $7,65.105$ & $2,30.106$ \\
& CV $(\%)$ & 16 & 22,8 & 19,6 & 16,9 \\
\hline
\end{tabular}

**: significativo a p < 0,01; G.L. = Graus de liberdade; S.Q. = Soma de Quadrados; CV = Coeficiente de Variação

Devido aos hipobiotos serem provenientes de polinização aberta, a diferenciação entre os modelos matemáticos descritores do crescimento e do acúmulo de massa da matéria seca (Figura 1) e de nutrientes (Figura 2 e 3) deve-se, além das características avaliadas e do período de cultivo, à variabilidade do material genético empregado, como também evidenciou Oliveira et al. (2005) e Perin et al. (2009) para a cultura da banana, caracterizando a influência genotípica sobre o crescimento da planta.

Com relação às épocas de coleta, verificouse aumento linear da altura e do diâmetro do caule, em decorrência do crescimento natural das mudas de caramboleiras, concordando com os resultados relatados por Freitas et al. (2011); Rozane et al. (2011a, 2011b); Hernandes et al. (2010), que trabalharam com mudas dessa frutífera cultivadas em hidroponia.

O lento crescimento dos hipobiotos até 50 DAT, neste caso, deve-se provavelmente ao estresse provocado pelo transplante e à adaptação do hipobioto ao meio de cultivo. Lima Filho et al. (1997) em estévia observaram que nos estágios iniciais, a massa vegetal é pequena, o que faz com que a taxa de crescimento seja proporcional ao tamanho do indivíduo. Desse modo, quanto maior a massa da planta mais rápida ela cresce, dentro de limites fisiológicos e da fase de desenvolvimento.

No período que compreende 50-75 DAT o hipobioto apresentou as maiores taxas de crescimento relativo, caracterizadas pelo grande desenvolvimento do caule, das folhas e das raízes (Tabela 3). Feltrim et al. (2008) evidenciam que, na fase final de desenvolvimento da planta, os aumentos no crescimento tornam-se progressivamente menores com o tempo, até que um patamar estável é atingido.

Para o presente experimento, entre 75-100 DAT e, mais especificamente, entre 100-125 DAT, houve redução na taxa de crescimento relativo (Tabela 3 ), mas isso não ocorreu devido à planta estar em final de ciclo, pois esta é perene e encontra-se ainda em estado de juvenilidade, ou seja, ainda não constitui a produção de estruturas reprodutivas (flores, frutos e sementes). $\mathrm{O}$ que pode explicar o ocorrido é o sombreamento causado pelo vigoroso crescimento e reduzido espaçamento entre as plantas. Contudo, o espaçamento empregado no experimento é o preconizado e utilizado no cultivo comercial, pois o objetivo nesta fase é obter o diâmetro do caule adequado para a realização da enxertia, o qual teve comportamento linear crescente (Figura 1a).

A produção de massa da matéria seca da planta inteira, ao final do experimento, foi de $23,12 \mathrm{~g}$ por planta, obedecendo à ordem: folhas $(56 \%)>$ caule $(25 \%)>$ raízes (19\%). Pelas curvas de crescimento (modelo logístico), o tempo necessário para os hipobiotos acumularem 50\% do máximo assintótico ocorreu aos 80; 106; 101 e 97 dias, respectivamente, para área foliar, massa da matéria seca da planta inteira, das folhas e das raízes. Resultados semelhantes 
em mudas de caramboleira foram obtidos por Freitas et al. (2011); Rozane et al., 2011a, 2011b e, em goiabeiras, por Franco et al. (2007) e Augostinho et al. (2008), que também constataram maior contribuição das folhas no acúmulo da massa da matéria seca da planta inteira. Esse fato ocorreu, provavelmente, devido às folhas serem os maiores drenos de assimilados (AUGOSTINHO et al., 2008; FRANCO et al., 2007), resultando em maior acúmulo da massa da matéria seca, pois, as raízes e o caule, não apresentavam, ainda, alta capacidade acumuladora de assimilados. Nesta fase de desenvolvimento inicial, a caramboleira concentrou o acúmulo de biomassa nas folhas, possivelmente para incrementar a área foliar e a taxa fotossintética.

Houve correlação positiva entre a massa de matéria seca da planta inteira do hipobioto e a altura $(\mathrm{r}=0,98 ; \mathrm{p}<0,01)$; entre o diâmetro do caule $(\mathrm{r}=0,98$; $\mathrm{p}<0,01)$ e a área foliar $(\mathrm{r}=0,98 ; \mathrm{p}<0,01)$, indicando que essas características apresentam comportamento semelhante e diretamente proporcional ao acúmulo da massa da matéria seca da planta inteira, sendo variáveis não destrutivas implicando no acúmulo de massa da matéria seca dos hipobiotos. Resultados semelhantes para as mesmas variáveis foram encontradas por Melo et al. (2005) com mudas de umbuzeiro, Franco et al. (2007) e Augostinho et al. (2008) com mudas de goiabeira.

O acúmulo de nutrientes, em função do tempo de cultivo, apresentou ajuste variável em função do órgão e do nutriente. Contudo, a maior ocorrência dos ajustes deu-se com o modelo logístico (Figura 2 e 3), o que corrobora com os resultados de Augostinho et al. (2008), que cultivaram goiabeiras sob condições

Figura 1 - Equações, valor de F e coeficiente de determinação $\left(\mathrm{R}^{2}\right)$ obtidos nos estudos de regressão sobre os efeitos do tempo de cultivo (dias) no diâmetro do caule $(\boldsymbol{\Delta})$ e na altura (অ) (a), na área foliar $(\boldsymbol{\Delta})$ (b) e a massa da matéria seca da planta inteira $(\diamond)$, das folhas $(\boldsymbol{\square})$, do caule $(\mathbf{\Delta})$ e das raízes (०) (c) dos hipobiotos de caramboleira, em função do tempo de cultivo em hidroponia (**: p <0,01)
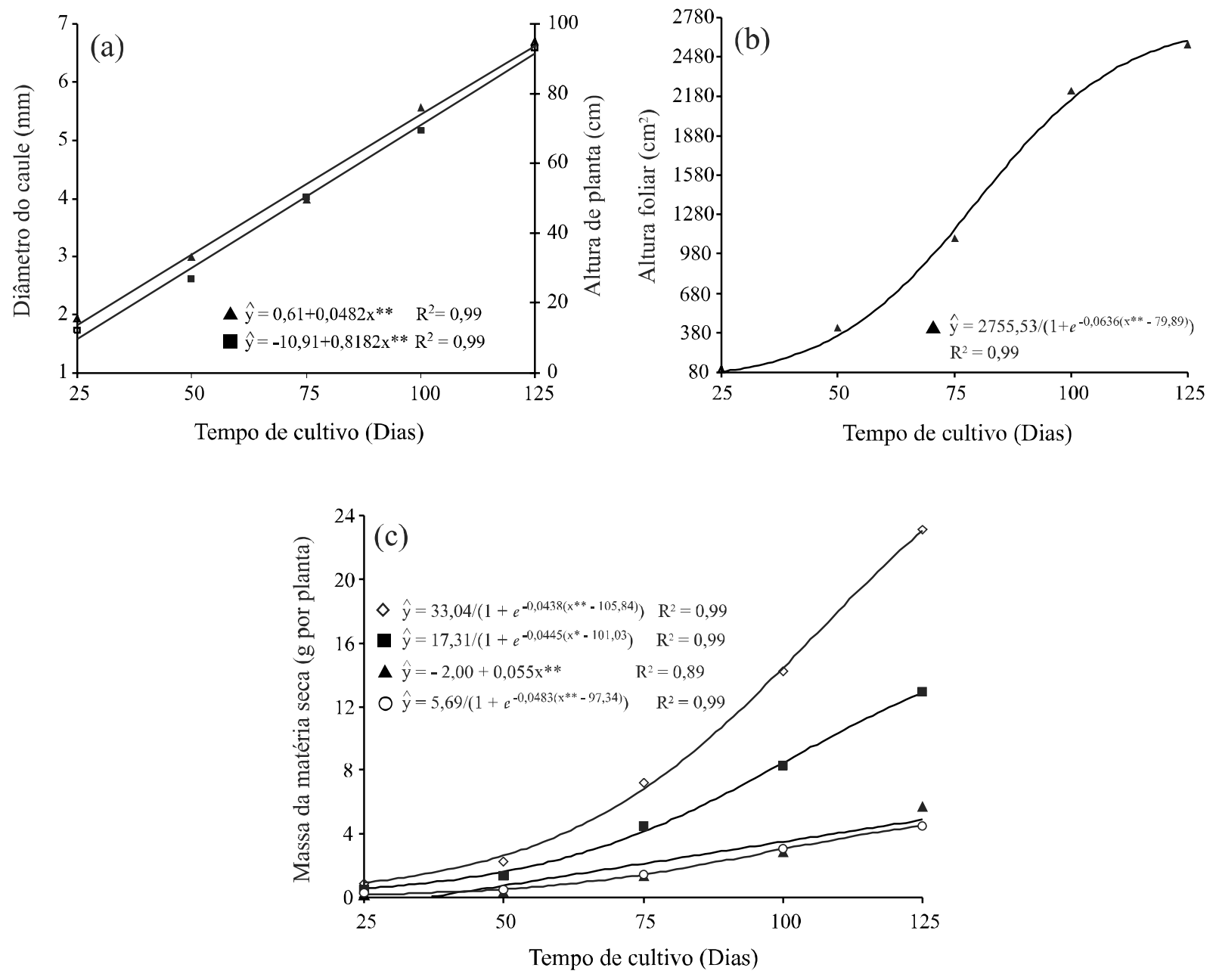
Figura 2 - Equações, valor de $\mathrm{F}$ e coeficiente de determinação $\left(\mathrm{R}^{2}\right)$ obtidos nos estudos de regressão sobre os efeitos do tempo de cultivo (dias) no acúmulo de $\mathrm{N}(\mathrm{a}), \mathrm{P}(\mathrm{b}), \mathrm{K}(\mathrm{c}), \mathrm{Ca}(\mathrm{d}), \mathrm{Mg}(\mathrm{e})$ e S (f) na planta inteira ( $\diamond)$, nas folhas (๘), no caule ( $\mathbf{\Delta}$ ) e nas raízes (o) em hipobiotos de caramboleira, em função do tempo de cultivo em hidroponia. (**: p < 0,01)
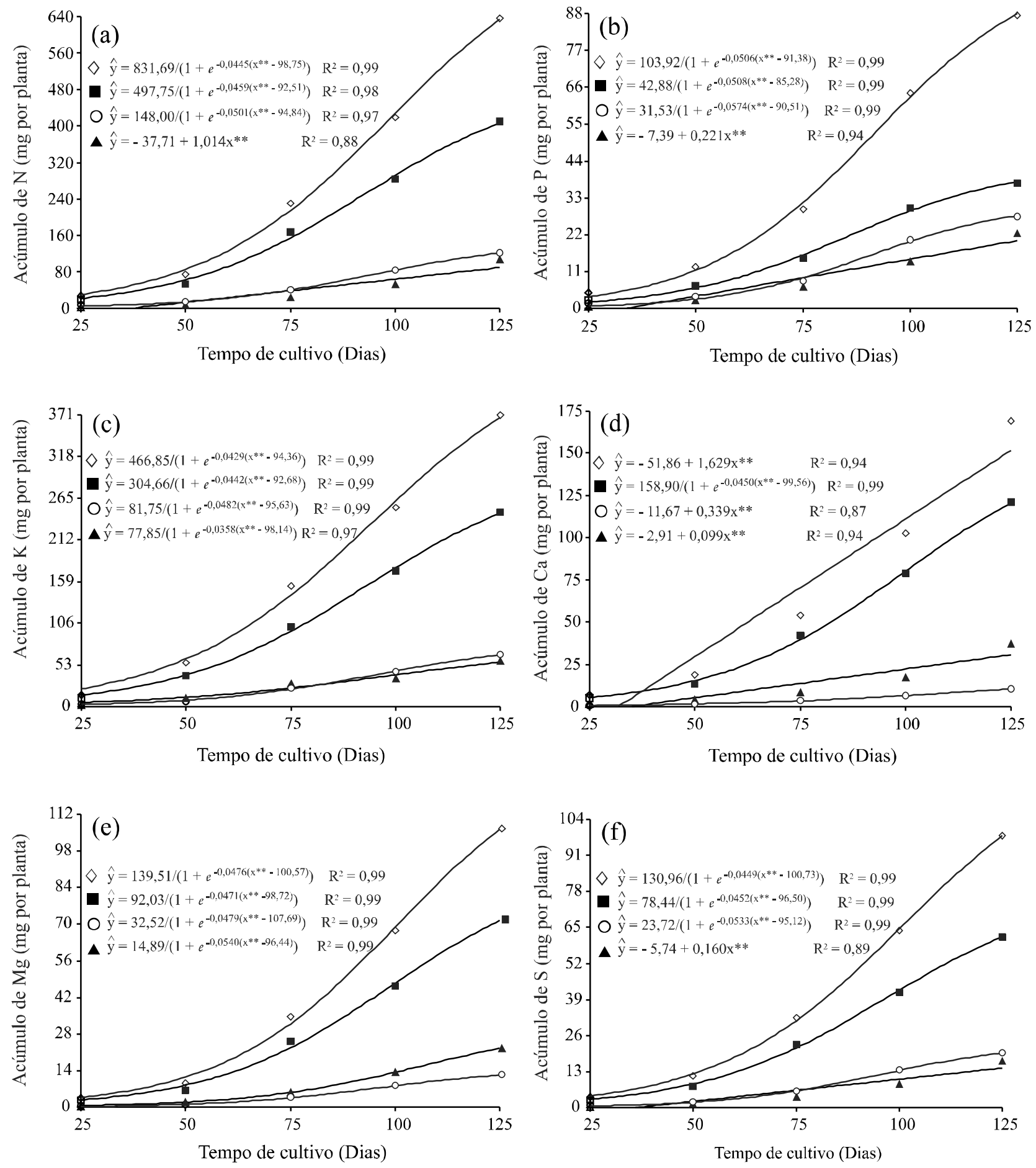

semelhantes às deste estudo. Diferenças nas funções de acúmulo de nutrientes para mudas de frutíferas são relatadas, ainda, por Barbosa, Soares e Crisóstomo

(2003) em gravioleiras; Franco et al. (2007) em goiabeiras; e Freitas et al. (2011) e Rozane et al., (2011a, 2011b) em caramboleiras. 
Entretanto, para o acúmulo de Ca (Figura 2d) e B (Figura 3a) nos órgãos estudados, destaca-se como ajuste mais adequado o modelo linear, o que poderia sugerir uma absorção mais rápida e contínua destes nutrientes pela muda, devido às suas funções estruturais e à imobilidade desses elementos quanto à redistribuição na planta.

Figura 3 - Equações, valor de $\mathrm{F}$ e coeficiente de determinação $\left(\mathrm{R}^{2}\right)$ obtidos nos estudos de regressão sobre os efeitos do tempo de cultivo (dias) no acúmulo de B (a), Cu (b), Fe (c), Mn (d) e Zn (e) na planta inteira ( $\diamond)$, nas folhas (•), no caule ( $\mathbf{\Delta}$ ) e nas raízes (o) em hipobiotos de caramboleira, em função do tempo de cultivo em hidroponia. (**: $p<0,01)$
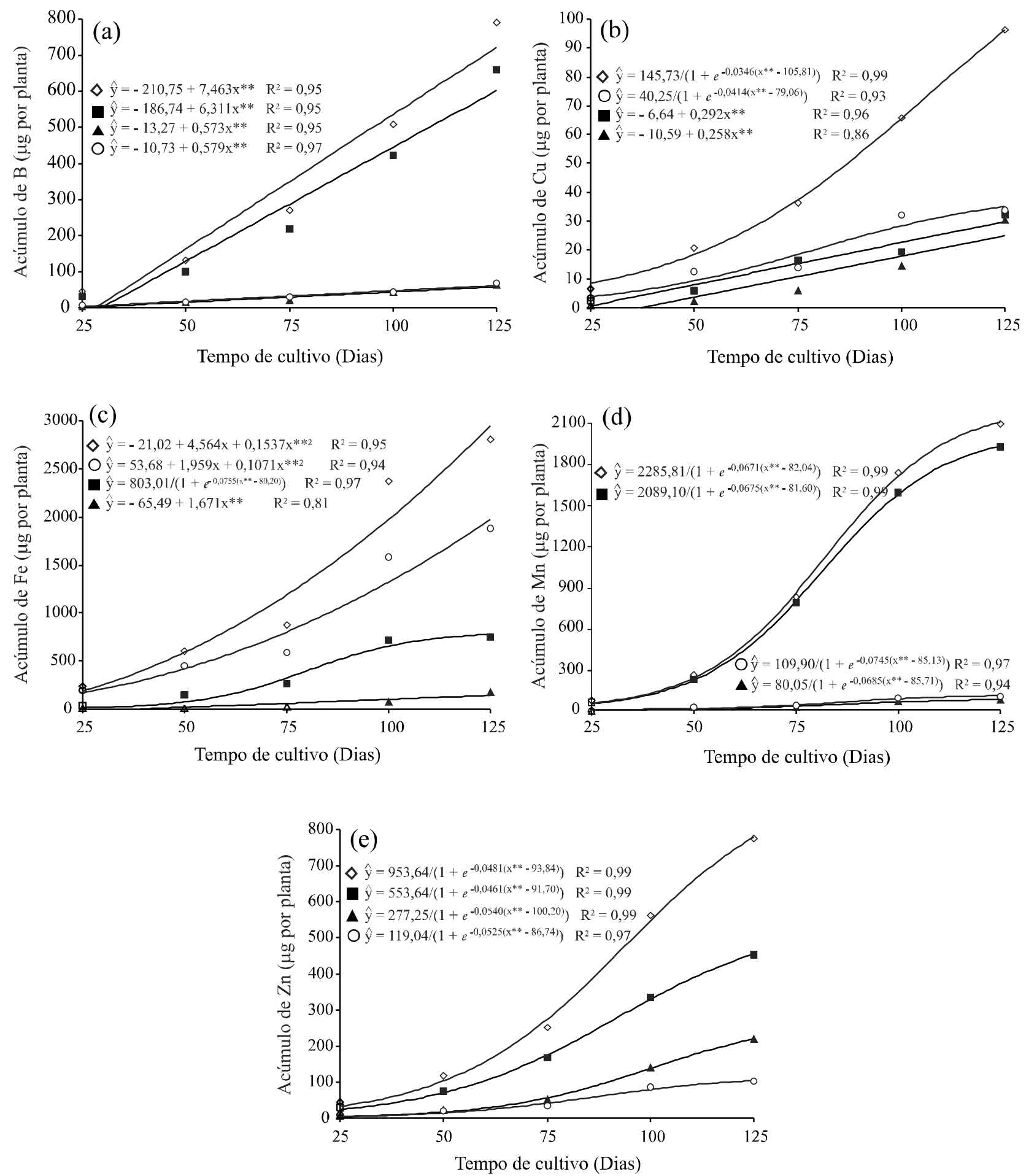
Tabela 3 - Taxa de crescimento relativo (TCR) nos órgãos de hipobiotos de caramboleira, em função do tempo de cultivo em hidroponia

\begin{tabular}{|c|c|c|c|c|}
\hline Período & Raízes & Caule & Folhas & Planta inteira \\
\hline Dias & ------------------. & ------ m & ---------- & - \\
\hline $25-50$ & 0,021 & 0,039 & 0,043 & 0,037 \\
\hline $50-75$ & 0,042 & 0,051 & 0,047 & 0,047 \\
\hline $75-100$ & 0,031 & 0,030 & 0,025 & 0,027 \\
\hline $100-125$ & 0,015 & 0,027 & 0,018 & 0,019 \\
\hline
\end{tabular}

Utilizando as curvas de acúmulo logístico da planta inteira (Figura 2e 3), o tempo necessário para que os hipobiotos acumulassem $50 \%$ do máximo assintótico ocorreu aos 99; 91; 94; 101; 101; 106; 82 e 94 dias, respectivamente, para N, P, K, $\mathrm{Mg}, \mathrm{S}, \mathrm{Cu}, \mathrm{Mn}$ e $\mathrm{Zn}$. Isso coincide com o mesmo período de acúmulo da massa da matéria seca, que atingiu metade do máximo assintótico entre 97 e 106 dias (Figura 1), além da similaridade entre a taxa média de acúmulo dos nutrientes e da massa da matéria seca (Figura 1, 2 e 3), evidenciando que a absorção de nutrientes seguiu o acúmulo da massa da matéria seca das plantas.

A similaridade das equações dos acúmulos de nutrientes acompanharem a massa da matéria seca, resultando na maior ocorrência dos ajustes ao modelo logístico, pode ser explicada pelo fato dos hipobiotos de caramboleira, nas presentes condições experimentais, possuírem em média $6,4 \%$ do peso dos nutrientes avaliados na massa da matéria seca total. Lima Filho e Malavolta (1997); Lima Filho et al. (1997) relataram que em cultivo de estévia, que a acumulação de nutrientes acompanha a taxa de crescimento da planta.

O acúmulo médio dos nutrientes nos órgãos obedeceu à sequência: folhas $(65 \%)$; caule $(17,5 \%)$ e raízes $(17,5 \%)$; quanto aos nutrientes o acúmulo médio foi: $\mathrm{N}>\mathrm{K}>\mathrm{Ca}>\mathrm{Mg}>\mathrm{S}>\mathrm{P}>\mathrm{Fe}>\mathrm{Mn}>\mathrm{B}>\mathrm{Zn}>\mathrm{Cu}$ (Figura 1 e 2). Resultados similares foram observados por Rozane et al. (2011a, 2011b) e Freitas et al. (2011) para caramboleiras, sob condições de cultivo semelhantes. Em mudas de goiabeira, Franco et al. (2007) e Augostinho et al. (2008) observaram que o acúmulo de macronutrientes deu-se nas folhas, respectivamente (70 e $65 \%$ ), no caule (10 e 18\%) e nas raízes (20 e 17\%).

A taxa de crescimento relativo (TCR) expressa o aumento da massa da matéria seca, por unidade de massa já existente, em um intervalo de tempo, a qual de modo geral para os hipobiotos acompanhou as taxas de absorção de nutrientes e a acumulação da massa da matéria seca. Após o transplante, valores máximos para as raízes, caule e folhas foram obtidos entre 50-75 DAT (Tabela 3), o que representa o segundo período de coleta, como também observaram Rozane et al. (2011b).
A partir da TCR, obteve-se a Taxa de Absorção Relativa de Nutriente (TARN), em toda a planta, ou seu acúmulo em um órgão específico (TALON), ou seja, Taxa de Acumulação Líquida Organogênica (Tabela 4). Portanto, a TARN e a TALON dependem da massa vegetal produzida e de um fator intrínseco ao metabolismo vegetal, ligado às necessidades fisiológicas da planta pelo nutriente.

De modo geral, as maiores TARNs ocorreram entre 25 e 75 DAT (Tabela 3), o que possivelmente tenha promovido os maiores valores de TCR (Tabela 4) no mesmo período. Somam-se a isso as condições adequadas de cultivo. Entretanto, a TALON, nos diversos órgãos, nem sempre acompanhou a TCR destes na planta. Assim, entre 25 e 50 DAT, a maior TALON no caule, em relação aos demais órgãos, ocorreu para $\mathrm{P}, \mathrm{K}, \mathrm{Ca}, \mathrm{Mg}$ e $\mathrm{Zn}$, enquanto o $\mathrm{N}, \mathrm{S}$, B e o Mn acumularam-se, preferencialmente, nas folhas, e o $\mathrm{Cu}$ e o $\mathrm{Fe}$, nas raízes. Para todos os macronutrientes, com exceção do S, Lima filho et al. (1997) observaram comportamento idêntico. Para os micronutrientes, o B, o Mn e o Zn também corroboram os resultados de Lima filho e Malavolta (1997). Em trabalho com mudas enxertadas de caramboleiras 'B-10' e 'Golden Star' Rozane et al. (2011a) observaram que, do total de nutrientes absorvidos, o acúmulo de $\mathrm{N}, \mathrm{K}, \mathrm{Ca}, \mathrm{Mg}, \mathrm{S}, \mathrm{B}$, $\mathrm{Mn}$ e $\mathrm{Zn}$ foi maior nas folhas, enquanto o Fe foi maior nas raízes, e o $\mathrm{Cu}$, no caule.

Em todos os períodos analisados, o Fe obteve a maior TALON nas raízes, o que possivelmente deve ter ocorrido devido ao meio de cultivo empregado, além da provável nãoremoção adequada de todo o elemento no procedimento de lavagem, devido à sua maior concentração na solução em comparação aos demais nutrientes e ao solo. O Mn apresentou, em todos os períodos analisados, a maior TALON nas folhas, corroborando as observações de Freitas et al. (2011) e Rozane et al. (2011a). Hernandes et al. (2011) enfatizam que a maior porcentagem (superior a 50\%) do Mn presente nas folhas de caramboleiras está fortemente associada às estruturas de compostos ou fazendo parte de complexos muito estáveis e insolúveis, como algumas proteínas.

De 50 a 75 DAT, com exceção do $P$, que teve maior direcionamento para o caule e raízes, e considerando as 
Tabela 4 - Taxa de acumulação líquida organogênica (TALON) e taxa de absorção relativa (TARN) de nutrientes nos órgãos de hipobiotos de caramboleira, em função do tempo de cultivo em hidroponia

\begin{tabular}{|c|c|c|c|c|c|c|c|c|c|c|c|c|}
\hline \multirow{2}{*}{ Órgãos } & Períodos & $\mathrm{N}$ & $\mathrm{P}$ & $\mathrm{K}$ & $\mathrm{Ca}$ & $\mathrm{Mg}$ & $\mathrm{S}$ & B & $\mathrm{Cu}$ & $\mathrm{Fe}$ & $\mathrm{Mn}$ & $\mathrm{Zn}$ \\
\hline & Dias & \multicolumn{6}{|c|}{ 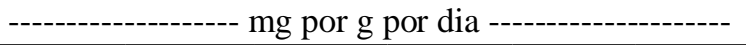 } & \multicolumn{5}{|c|}{ 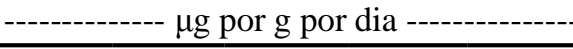 } \\
\hline \multicolumn{13}{|c|}{$\begin{array}{l}\text { TALON } \\
\end{array}$} \\
\hline \multirow{4}{*}{ Raízes } & $25-50$ & 0,723 & 0,187 & 0,364 & 0,114 & 0,043 & 0,134 & 0,946 & 0,933 & 26,744 & 0,780 & 1,332 \\
\hline & $50-75$ & 1,176 & 0,228 & 0,768 & 0,078 & 0,127 & 0,166 & 0,638 & 0,072 & 6,259 & 0,529 & 0,548 \\
\hline & $75-100$ & 0,845 & 0,229 & 0,398 & 0,058 & 0,084 & 0,147 & 0,224 & 0,341 & 18,783 & 1,125 & 0,998 \\
\hline & $100-125$ & 0,396 & 0,075 & 0,230 & 0,045 & 0,045 & 0,065 & 0,264 & 0,017 & 3,154 & 0,151 & 0,177 \\
\hline \multirow{4}{*}{ Caule } & $25-50$ & 0,873 & 0,306 & 1,489 & 0,415 & 0,225 & 0,190 & 1,937 & 0,243 & 0,862 & 1,965 & 2,748 \\
\hline & $50-75$ & 0,842 & 0,216 & 0,982 & 0,235 & 0,209 & 0,124 & 0,245 & 0,187 & 0,846 & 0,011 & 1,554 \\
\hline & $75-100$ & 0,570 & 0,146 & 0,126 & 0,179 & 0,147 & 0,095 & 0,428 & 0,169 & 0,970 & 0,939 & 1,745 \\
\hline & $100-125$ & 0,527 & 0,083 & 0,213 & 0,191 & 0,091 & 0,079 & 0,201 & 0,155 & 1,029 & 0,078 & 0,766 \\
\hline \multirow[t]{4}{*}{ Folhas } & $25-50$ & 1,681 & 0,203 & 1,350 & 0,390 & 0,188 & 0,240 & 3,154 & 0,175 & 5,123 & 7,548 & 2,107 \\
\hline & $50-75$ & 1,742 & 0,123 & 0,946 & 0,443 & 0,283 & 0,229 & 1,807 & 0,158 & 1,808 & 8,793 & 1,403 \\
\hline & $75-100$ & 0,744 & 0,098 & 0,465 & 0,236 & 0,137 & 0,122 & 1,323 & 0,019 & 2,918 & 5,366 & 1,093 \\
\hline & $100-125$ & 0,487 & 0,029 & 0,285 & 0,162 & 0,098 & 0,077 & 0,912 & 0,049 & 0,112 & 1,323 & 0,453 \\
\hline \multicolumn{13}{|c|}{ TARN } \\
\hline & $25-50$ & 1,293 & 0,215 & 1,109 & 0,320 & 0,155 & 0,204 & 2,368 & 0,382 & 10,037 & 4,849 & 1,999 \\
\hline Planta & $50-75$ & 1,465 & 0,161 & 0,915 & 0,331 & 0,237 & 0,197 & 1,289 & 0,146 & 2,544 & 5,534 & 1,255 \\
\hline \multirow[t]{2}{*}{ Inteira } & $75-100$ & 0,730 & 0,134 & 0,385 & 0,188 & 0,128 & 0,122 & 0,921 & 0,114 & 5,804 & 3,625 & 1,200 \\
\hline & $100-125$ & 0,477 & 0,050 & 0,257 & 0,144 & 0,086 & 0,075 & 0,618 & 0,066 & 0,939 & 0,803 & 0,467 \\
\hline
\end{tabular}

observações feitas para Mn e Fe, houve quase predomínio referente ao direcionamento dos demais nutrientes para as folhas, que, no referido período tiveram juntamente com o caule a maior TCR entre os órgãos (Tabela 4).

Apesar de haver semelhança da TALON entre os períodos de 75-100 e 100-125 DAT quanto ao órgão acumulado, houve variação entre os nutrientes quanto ao órgão de destino, sendo que a maior acumulação não ocorreu no caule, como se poderia supor, em virtude da alta TCR do órgão.

Sendo a TALON o resultado dos processos que consideram tanto a acumulação quanto a redistribuição do nutriente para outros órgãos ou para o meio externo (LIMA FILHO et al., 1997; LIMA FILHO; MALAVOLTA, 1997), seria possível observar resultados negativos, indicando assim perda líquida de um dado elemento, devido à redistribuição, ou, ainda, por acumulação negativa. Contudo, a não-ocorrência deste fato faz supor que os hipobiotos se encontravam em pleno desenvolvimento vegetativo, com constante absorção de nutrientes. Além disso, as condições de cultivo hidropônico, bem como a solução empregada e a periodicidade de troca da mesma, não limitaram o desenvolvimento das plantas, sendo que a diagnose visual não constatou sintomas de toxicidade e/ou deficiência nutricional, o que era esperado devido ao emprego da solução nutritiva de Furlani et al. (1999), indicada como adequada para o cultivo de mudas de caramboleira, segundo Rozane et al. (2007).

\section{CONCLUSÕES}

1. A ordem decrescente dos nutrientes acumulados em cada hipobioto produzido é de (em $\mathrm{mg}$ por planta): $\mathrm{N}=634 ; \mathrm{K}=368 ; \mathrm{Ca}=152 ; \mathrm{Mg}=106 ; \mathrm{S}=98 ; \mathrm{P}=88$ (em $\mu$ g por planta) de: $\mathrm{Fe}=2963 ; \mathrm{Mn}=2165 ; \mathrm{B}=722$; $\mathrm{Zn}=780$, e $\mathrm{Cu}=96$. O acúmulo médio de nutrientes é maior nas folhas $>$ caule $=$ raízes. $\mathrm{O}$ período de maior exigência de nutrientes pelo hipobioto é compreendido entre 25-75 dias após o transplantio;

2. Apesar das diferentes taxas de acumulação líquida dos nutrientes, nas diferentes partes da caramboleira, nem sempre acompanham a taxa de acumulação de nutrientes do respectivo órgão, observamos que a TCR apresentou os maiores valores entre 50-75 DAT, e a TALON entre o período de 75-125 DAT; 
3. A marcha de absorção dos nutrientes e a taxa de acúmulo médio de nutrientes seguem o acúmulo da massa da matéria seca dos hipobiotos.

\section{REFERÊNCIAS}

AL-YAHYAI R. et al. Effect of soil water depletion on growth, yield, and fruit quality of carambola in gravelly loam soil. Proceedings of the Florida State Horticultural v. 118, p. 237-241, 2005.

AUGOSTINHO, L. M. D. et al. Marcha de absorção de macro e micronutrientes em mudas de goiabeira 'Pedro Sato'. Bragantia, v. 67, n. 3, p. 563-568, 2008.

BATAGLiA, O. C. et al. Métodos de análise química de plantas. Campinas: Instituto Agronômico, 1983. 48 p. (Boletim Técnico, 78).

BARBOSA, J. C.; MALDONADO JÚNIOR, W. Software AgroEstat:Sistema de análises estatísticas de ensaios agronômicos. Universidade Estadual Paulista, Faculdade de Ciências Agrárias e Veterinárias, Câmpus de Jaboticabal, Brasil, 2009.

BARBOSA, Z.; SOARES, I.; CRISÓTOMO, L. A. Crescimento de nutrientes por mudas de gravioleira. Revista Brasileira de Fruticultura, v. 25, n. 3, p. 519-522, 2003.

BASTOS, D. C. A cultura da carambola. Revista Brasileira de Fruticultura, v. 26, n. 2 p. 1-2, 2004.

DONADIO, L. C. et al. Caramboleira (Averrhoa carambola L.). Jaboticabal: Sociedade Brasileira de Fruticultura. 2001. 81 p.

FELTRIM,A.L. et al. Crescimento e acúmulo de macronutrientes em chicória coberta e não coberta com polipropileno. Horticultura Brasileira, v. 26, n. 1, p. 50-55, 2008.

FRANCO, C. F. et al. Curva de crescimento e marcha de absorção de macronutrientes em mudas de goiabeira. Revista Brasileira de Ciência do Solo, v. 31, n. 6, p. 1429-1437, 2007.

FRANCO, C. F. et al. Marcha de absorção dos micronutrientes para mudas de goiabeiras cultivares Paluma e Século XXI. Bragantia, v. 67, n. 1, p. 83-90, 2008.

FREITAS, N. et al. Marcha de absorção de nutrientes e crescimento de mudas de caramboleira enxertada com cultivar Nota-10. Semina. Ciências Agrárias, Londrina, v. 32, n. 4, p. 1231-1242, 2011.

FURLANI, P. R. et al. Cultivo hidropônico de plantas. Campinas: Instituto Agronômico de Campinas. 1999. 52 p. (Boletim Técnico, 180).
HERNANDES, A. et al. Fracionamento de manganês acumulado nos tecidos de mudas de caramboleira. Revista Brasileira de Ciência do Solo, v. 35, n. 05, p. 1679-1686, 2011.

HERNANDES, A. et al. Influência do manganês no crescimento e na composição mineral de mudas de caramboleira. Revista Brasileira de Fruticultura, v. 32, n. 4, p.1220-1230, 2010.

HOFFMAM, R.; VIEIRA, S. Análise de regressão, São Paulo, Ed. Huitec-Edusp, 1977. 339 p.

LIMAFILHO, O. F. et al. Absorção e acumulação de nutrientes em estévia [Stevia rebaudiana (Bert.) Bertoni]: II. Micronutrientes. Scientia Agricola, v. 54, n. 1/2, p. 23-30, 1997.

LIMA FILHO, O. F.; MALAVOLTA, E. Absorção e acumulação de nutrientes em estévia [Stevia rebaudiana (Bert.) Bertoni]: I. Macronutrientes. Scientia Agricola, v. 54, n. 1/2, p. 14-22, 1997.

MALAVOLTA, E. et al. Avaliação do estado nutricional das plantas: princípios e aplicações. 2.ed. Piracicaba: POTAFOS, 1997. $319 \mathrm{p}$.

MELO, A. S. et al. Desenvolvimento de porta-enxertos de umbuzeiro em resposta à adubação com nitrogênio e fósforo. Ciência Rural, v. 35, n. 2, p. 324-331, 2005.

OLIVEIRA, F. H. T. et al. Desenvolvimento de um sistema de recomendação de adubação para a cultura da bananeira. Revista Brasileira de Ciência do Solo, v. 29, n. 1, p. 131-143, 2005.

PERIN, A. et al. Desempenho de bananeiras consorciadas com leguminosas herbáceas perenes. Ciência e Agrotecnologia, v. 33, n. 6 , p. $1511-1517,2009$.

ROZANE, D. E. et al. Eficiência de absorção, transporte e utilização de macronutrientes por porta-enxertos de caramboleira, cultivados em soluções nutritivas. Ciência e Agrotecnologia, v. 31, n. 4, p. 1020-1026, 2007.

ROZANE, D. E. et al. Produção de mudas de caramboleiras B-10 e Golden Star: II - Marcha de absorção e acúmulo de nutrientes. Revista Brasileira de Fruticultura, v. 33, n. 4, p. 1308-1321, 2011a.

ROZANE, D. E. et al. Produção de mudas de caramboleiras B10 e Golden Star: I - Parâmetros biológicos. Revista Brasileira de Fruticultura, v. 33, n. 4, p. 1300-1307, 2011 b.

THOMPSON, M. et al. Harmonized guidelines for single laboratory validation of methods of analysis (IUPAC Technical Report). Pure and Applied Chemistry, v. 74, n. 5, p. 835-855, 2002.

WELBANK, P. J. The effects of competition with Agropyron repens and of nitrogen and water supply on the nitrogen content of Impatiens parviflora. Annals of Botany, v. 26, n. 103, p. 361-373, 1962. 